Article

\title{
Biodegradable Ceramics Consisting of Hydroxyapatite for Orthopaedic Implants
}

\author{
Thomas K. Monsees ${ }^{1}$ (1), Funda Ak Azem ${ }^{2}$, Cosmin Mihai Cotrut ${ }^{3,4}$, Mariana Braic ${ }^{5}$, \\ Radwan Abdulgader ${ }^{1}$, Iulian Pana ${ }^{5}$, Isil Birlik ${ }^{2}$, Adrian Kiss ${ }^{5}$, Robin Booysen ${ }^{1}$ \\ and Alina Vladescu $4,5, *$ \\ 1 Department of Medical Biosciences, University of the Western Cape, Bellville 7535, South Africa; \\ tmonsees@uwc.ac.za (T.K.M.); 2632028@myuwc.ac.za (R.A.); 3522606@myuwc.ac.za (R.B.) \\ 2 Metallurgical and Materials Engineering Department, Engineering Faculty, Dokuz Eylul University, \\ Tinaztepe Campus, Izmir 35397, Turkey; funda.ak@deu.edu.tr (F.A.A.); isil.kayatekin@deu.edu.tr (I.B.) \\ 3 Faculty of Material Science and Engineering, University Politehnica of Bucharest, 313 Spl. Independentei, \\ Bucharest 060042, Romania; cosmin.cotrut@upb.ro \\ 4 Department of Experimental Physics, National Research Tomsk Polytechnic University, Lenin Avenue 43, \\ Tomsk 634050, Russia \\ 5 National Institute for Optoelectronics, 409 Atomistilor St., Magurele 77125, Romania; \\ mariana.braic@inoe.ro (M.B.); iulian.pana@inoe.ro (I.P.); kadremil@yahoo.com (A.K.) \\ * Correspondence: alinava@inoe.ro; Tel.: +4-21-457-5759
}

Academic Editor: Yuelian Liu

Received: 11 September 2017; Accepted: 27 October 2017; Published: 3 November 2017

\begin{abstract}
This study aims to analyze hydroxyapatite (HAP) coatings enriched with $\mathrm{Mg}$ and $\mathrm{Ti}$ prepared by a magnetron sputtering technique on Ti6Al4V substrate. For preparation of the coatings, three magnetron targets $\left(\mathrm{HAP}, \mathrm{MgO}\right.$ and $\mathrm{TiO}_{2}$ ) were simultaneously co-worked. The concentration of $\mathrm{Mg}$ added was varied by modifying the power applied to the $\mathrm{MgO}$ target. In all coatings, the $\mathrm{Ti}$ concentration was maintained constant by keeping the same cathode power fed during the whole deposition. The influence of different $\mathrm{Mg}$ dopant contents on the formation of phase, microstructure and morphology of the obtained Ti-doped HAP coatings were characterized by Fourier transform infrared spectroscopy (FTIR) and scanning electron microscopy (SEM). Moreover, the effects of Mg addition upon corrosion, mechanical and biological properties were also investigated. $\mathrm{Mg}$ - and Ti-doped HAP coating obtained at low radio-frequency (RF) power fed to the $\mathrm{MgO}$ target provided material with high corrosion resistance compared to other coatings and bare alloy. A slight decrease in hardness of the coatings was found after the $\mathrm{Mg}$ addition, from 8.8 to $5.7 \mathrm{GPa}$. Also, the values of elastic modulus were decreased from 87 to $53 \mathrm{GPa}$, this being an advantage for biomedical applications. The coatings with low $\mathrm{Mg}$ concentration proved to have good deformation to yielding and higher plastic properties. Biological test results showed that the novel surfaces exhibited excellent properties for the adhesion and growth of bone cells. Moreover, early adherent vital cell numbers were significantly higher on both coatings compared to Ti6Al4V, suggesting that Mg ions may accelerate initial osteoblast adhesion and proliferation.
\end{abstract}

Keywords: hydroxyapatite; corrosion; roughness; nanoindentation; osteoblasts; magnetron sputtering

\section{Introduction}

Calcium phosphate $(\mathrm{CaP})$ coatings promote bone growth on the interface between a bone and an implant [1]. Therefore, CaPs are commonly used to coat orthopedic and dental implants [2-4]. CaP-based coatings, such as hydroxyapatite (HAP) and tricalcium phosphate (TCP), are known to have good bioactive ability and, consequently, to promote the regeneration of bones [5]. HAP has 
been extensively considered as a good candidate for coating metallic implants due to its similar morphology and composition with the mineral phase of bone [6]. It has been used as a coating to improve the osseoconductivity of metallic implants, but due to the HAP's lack of mechanical strength, its application for working under load-bearing conditions is limited [7,8]. Nevertheless, biological apatite is different from pure and synthetically produced HAP [6]. Different elements present in biological apatite play an important role in bone formation and normal tissue functions [7]. Hence, the use of substituted HAP that incorporates different ions has been studied in order to control osteoblastic behavior of HAP coatings such as silicon $\left(\mathrm{SiO}_{4}{ }^{4-}\right)$, magnesium $\left(\mathrm{Mg}^{2+}\right)$, carbonate $\left(\mathrm{CO}_{3}{ }^{2-}\right)$, zinc $\left(\mathrm{Zn}^{2+}\right)$, fluoride, $\left(\mathrm{F}^{-}\right)$, potassium $\left(\mathrm{K}^{-}\right)$, cerium $\left(\mathrm{Ce}^{4+} / \mathrm{Ce}^{3+}\right)$ or strontium $\left(\mathrm{Sr}^{2+}\right)$. These ions are substituted into the HAP lattice to mimic the complex chemistry of human bone [6]. There have been many studies which show that a single dopant affects the HAP structure. Magnesium is an element related to biological apatite. The replacement of $\mathrm{Ca}^{2+}$ by $\mathrm{Mg}^{2+}$ in biological HAP leads to bone homeostasis metabolism, stimulates osteogenesis, and enhances the material's resistance to mechanical stress [9]. The reduced amount of $\mathrm{Mg}$ in bone unfavorably disturbs the stages of skeleton metabolism, promoting bone growth, by decreasing the activity of osteoblasts and weakening bone strength [10]. During the initial steps of osteogenesis, $\mathrm{Mg}$ also functions as a growth factor, and hence induces the formation of bone. In human bones, the carbonate and $\mathrm{Mg}$ ions are found to be of about $5.8 \mathrm{wt} \%$ and $0.55 \mathrm{wt} \%$, respectively [11]. Despite their minimal extent, these elemental substitutions are of great importance for biological functions and also for relations concerning bone mineral and CaP-based coatings deposited on implants in terms of chemical, physical, structural and mechanical properties, solubility and dissolution rate [12]. Titanium was chosen based on certain criteria: besides being a well-recognized biomaterial, titanium easily forms stable oxides at the surface due to its high affinity for oxygen, and thus promotes cell growth [13]. Lósarczyk et al. have prepared titanium-doped hydroxyapatite ceramics to evaluate physicochemical and biological properties, and their biological studies confirmed high biocompatibility of Ti-modified hydroxyapatite [14]. On the other hand, there are few studies on the effects of co-dopants on the characteristics of HAP.

Many methods have been employed to produce such biocompatible coatings on metals for biomedical applications: plasma-spraying, electrophoretic deposition, laser deposition, magnetron sputtering, and micro-arc methods. Nevertheless, each of these methods has limitations, and they are often the cause of low adhesion strength to the substrate [15]. By comparing all the above mentioned methods, radio-frequency (RF) magnetron sputtering has proved to be a particularly suitable method for the preparation of biocompatible ceramic coatings (based on Ca-P systems), due to its ability to offer control of the properties and enhanced substrate-coating adhesion $[7,16]$. Furthermore, RF magnetron sputtering is a simple technique that permits the simultaneous use of multiple target materials, this advantage being useful for the preparation of HAP coatings.

This study aims to analyze the influence of Mg incorporation in a Ti-doped HAP coating system in terms of structural, mechanical, corrosion and biological properties. In our previous study, enrichment of the HAP structure with Ti was successfully accomplished on Ti6Al4V alloy substrate by the magnetron sputtering system and its properties were investigated in terms of Ti addition to the HAP structure [13,17]. Therefore, this study is focused on the effect of Mg incorporation into HAP-Ti coatings for enhanced biological properties. The enriched anti-microbial abilities of HAP-Ti [18-21], corroborated by its good biocompatible properties, suggest these coatings can be valuable as an alternative to synthetic HAP for achieving proper biocompatible coatings for depositing implants used in dentistry or other biomedical fields.

\section{Materials and Methods}

\subsection{Preparation of the Coatings}

SiC abrasive paper (grit 2000) was used for grounding the Ti6Al4V alloy (BibusMetalsAG) substrates. Then, the substrates were polished and ultrasonically washed with isopropyl alcohol 
and water for $10 \mathrm{~min}$. All substrates were then dried at $120^{\circ} \mathrm{C}$ for $1 \mathrm{~h}$. Before deposition, the substrates were positioned on a rotating holder and were bombarded by $\mathrm{Ar}^{+}(1 \mathrm{keV} ; 5 \mathrm{~min})$. The silicon wafers were also used as substrates for the determination of the coatings' phase composition.

The coatings were produced by a magnetron sputtering system using three magnetrons ( 1 in. diameter) made of $\mathrm{HAP}, \mathrm{TiO}_{2}$ and $\mathrm{MgO}$ (99.9\% purity, Kurt J. Lesker Company, Hastings, UK). The deposition parameters and nomenclature of the coatings were indexed in Table 1 . The RF power fed to the HAP and $\mathrm{TiO}_{2}$ cathodes was kept constant at 50 and $25 \mathrm{~W}$, respectively. RF power fed to the $\mathrm{MgO}$ cathode was varied at 25 and $50 \mathrm{~W}$. The coatings hereafter will be labeled as TM-1 and TM-2, respectively. The HAP-Ti coating without $\mathrm{Mg}$ was used as a reference coating (TM-0). The distance between the targets and the substrate holder was $12 \mathrm{~mm}$. The deposition temperature was chosen as $700{ }^{\circ} \mathrm{C}$ based on previous results [22].

Table 1. Deposition parameters and nomenclature of the coatings.

\begin{tabular}{cccccccc}
\hline \multirow{2}{*}{ Identification } & $\begin{array}{c}\text { Base Pressure } \\
\left(\times \mathbf{1 0}^{-\mathbf{4}} \mathbf{P a}\right)\end{array}$ & $\begin{array}{c}\text { Ar Pressure } \\
\left(\times \mathbf{1 0}^{-\mathbf{1}} \mathbf{P a}\right)\end{array}$ & $\begin{array}{c}\mathbf{H A P} \\
\text { Cathode }\end{array}$ & $\begin{array}{c}\mathrm{TiO}_{\mathbf{2}} \\
\text { Cathode }\end{array}$ & $\begin{array}{c}\mathbf{M g O} \\
\text { Cathode }\end{array}$ & $\begin{array}{c}\text { Substrate } \\
\text { Bias Voltage } \\
(\mathbf{V})\end{array}$ & $\begin{array}{c}\text { Deposition } \\
\text { Temperature } \\
\left({ }^{\circ} \mathbf{C}\right)\end{array}$ \\
\hline $\mathrm{TM}-0$ & \multirow{2}{*}{1.3} & 6.6 & 50 & 25 & - & & \\
$\mathrm{TM}-1$ & & & 50 & 25 & 25 & -60 & 700 \\
$\mathrm{TM}-2$ & & & 50 & 25 & 50 & & \\
\hline
\end{tabular}

\subsection{Elemental Composition, Chemical Binding, Morphology and Mechanical Properties}

Evidence of elemental composition was provided through energy-dispersive X-ray spectroscopy (EDS-SEM-TM3030Plus, Bruker, Berlin, Germany). Fourier transform infrared spectroscopy (FTIR) was performed using a Jasco FTIR 6300 spectrometer (Tokyo, Japan) at a resolution of $4 \mathrm{~cm}^{-1}$ and 150 scans, using the transmission configuration for the identification of the chemical groups. Topography was evaluated by an atomic force microscope (AFM) (INNOVA, Veeco, Berlin, Germany) running in the tapping mode, from $3 \times 3 \mu \mathrm{m}^{2}$ area scans. Based on AFM images, the following roughness parameters were calculated: root-mean-square roughness $(\mathrm{rms})$, skewness $\left(S_{\mathrm{k}}\right)$ and kurtosis $(K)$.

A surface profiler (Dektak 150, Bruker, Berlin, Germany) was used for determining the roughness parameters. The testing conditions were: investigated area $800 \mu \mathrm{m} \times 800 \mu \mathrm{m}$, a low-inertia stylus sensor with $12.5 \mathrm{~mm}$ radius, $5 \mathrm{mg}$ contact force, and $20 \mu \mathrm{m} / \mathrm{s}$ scan speed. The $R_{\mathrm{a}}$ (average roughness), rms and $S_{\mathrm{k}}$ parameters were calculated on each coating before and after corrosion measurements.

Nanoindentation tests were performed with a NanoTest device (Fischer-Cripps Lab. Pty. Limited, Sydney, Australia), using a Berkovich indenter (face angle of $65.3^{\circ}$ ). For calculating penetration depth $(h)$, elastic modulus $(E)$, and hardness $(H)$, the load-unload curves were applied from 1.0 to $5.0 \mathrm{mN}$. The position of each measure was randomly selected. The holding time at the maximum load was $5 \mathrm{~s}$ in order to reduce the creep effect, which could affect the shape of the unload curve and, at the end, the values of the elastic modulus and hardness of the HAP coatings. The values of $E$ and $H$ were averaged over five measurements. The values of $E$ and $H$ were extracted using the method reported by Oliver and Pharr [23].

\subsection{In Vitro Corrosion Behaviour}

The corrosion behaviour was observed by electrochemical tests in simulated body fluid (SBF) solution (composition presented in [24] $\mathrm{pH}=7.2$ ) at $37 \pm 0.4{ }^{\circ} \mathrm{C}$, using a PARSTAT 4000 system (Princeton Applied Research, Princeton, NJ, USA). Each sample (working electrode) was inserted in a Teflon holder and an area of $1 \mathrm{~cm}^{2}$ was in contact with corrosive solution. The electrochemical tests were operated using a Pt foil as counter electrode and saturated calomel (SCE) as reference electrode. The scanning rate was of $1 \mathrm{mV} / \mathrm{s}$, a value recommended by standard ASTM G5-94 [25] (reapproved 1999). Also, a magnetic microstirrer (VelpScientifica, Bohemia, NY, USA) with speed range $300 \mathrm{rpm}$ 
was used. The electrochemical tests involved two steps: recording of the open-circuit potential $\left(E_{\mathrm{OC}}\right)$ for $6 \mathrm{~h}$, and Tafel curves from -0.25 to $+0.25 \mathrm{~V}$ vs. $E_{\mathrm{OC}}$.

\subsection{In Vitro Biological Assessment}

Human osteogenic sarcoma cells (SaOS-2) were purchased from the American Type Tissue Collection (ATCC HTB 85, Manassas, VA, USA) and cultured in 85\% McCoy's 5A medium, supplemented with $15 \%$ fetal bovine serum and $1 \%$ penicillin/streptomycin at $37^{\circ} \mathrm{C}$ and $5 \% \mathrm{CO}_{2}$. Cells at densities ranging from 10,000 (3 days) to 15,000 (1 day) cells $/ \mathrm{cm}^{2}$ were seeded onto coated or pure Ti6Al4V discs ( $15 \mathrm{~mm}$ diameter, $1 \mathrm{~mm}$ thick). The medium was changed every second day.

Cell viability was assessed by live/dead fluorescence staining using calcein-AM (Invitrogen, Waltham, MA, USA) and propidium iodide (PI, Sigma, Schnelldorf, Germany). On day 1 or 3 after seeding, cells were washed with HEPES buffered saline (HBSS) and stained with calcein-AM $(2 \mu \mathrm{M})$ and PI $(4 \mu \mathrm{M})$ in HBSS for $30 \mathrm{~min}$ at room temperature (RT) in the dark. Thereafter, staining solution was removed and samples were mounted upside down into coverslip bottom dishes (SPL, Gyeonggi-do, South Korea) using a drop of ProLong Diamond antifade solution (Molecular Probes, Eugene, OR, USA). Samples were immediately photographed and analyzed with Axiovision software (version 4.8) and an Axiovert 200 microscope (Zeiss, Göttingen, Germany) using appropriate filters. For each sample, at least 5 random microscopic visual fields were considered for cell counts.

After 1 or 3 days of culture, cells were washed using phosphate-buffered saline (PBS), fixed with $4 \%$ formalin ( $5 \mathrm{~min}, \mathrm{RT}$ ), permeabilized using $0.5 \%$ Triton X-100 (6 min, RT), and incubated with 1\% bovine serum albumin in PBS (10 min, RT) to block unspecific bindings. After washing with PBS, cells were incubated with $0.1 \mu \mathrm{M}$ of phalloidin-TRITC (Sigma, Schnelldorf, Germany) for $1 \mathrm{~h}$ at RT to detect actin filaments. Thereafter, cells were washed three times with PBS. Cell nuclei were made evident by incubating with $1 \mu \mathrm{g} / \mathrm{mL}$ DAPI (Sigma, Schnelldorf, Germany) for $5 \mathrm{~min}$ at RT. Samples were photographed by fluorescence microscopy (Zeiss, Göttingen, Germany) using appropriate filters.

\section{Results and Discussion}

\subsection{Chemical Binding and Elemental Composition}

Elemental composition was analyzed on coating deposited on Si substrate for eliminating the effect of the Ti content from the Ti6Al4V alloy substrate. The EDS results are illustrated in Table 2. $\mathrm{The} \mathrm{Ca} / \mathrm{P}$ ratio is not affected by $\mathrm{Mg}$ or Ti addition. The $\mathrm{Mg}$ content increases as $\mathrm{RF}$ power is fed to the $\mathrm{MgO}$ target, as was intended.

Table 2. Energy-dispersive X-ray spectroscopy (EDS) results of the coatings.

\begin{tabular}{ccccccc}
\hline Coatings & Ca & $\mathbf{P}$ & Ti & Mg & O & Ca/P \\
\hline TM-0 & $5.9 \pm 0.2$ & $3.6 \pm 0.2$ & $8.9 \pm 0.3$ & - & $81.6 \pm 2.8$ & 1.64 \\
TM-1 & $5.8 \pm 0.2$ & $3.5 \pm 0.1$ & $8.3 \pm 0.3$ & $3.1 \pm 0.03$ & $79.3 \pm 2.4$ & 1.66 \\
TM-2 & $6.2 \pm 0.2$ & $3.7 \pm 0.1$ & $8.1 \pm 0.2$ & $9.2 \pm 0.1$ & $72.8 \pm 2.1$ & 1.68 \\
\hline
\end{tabular}

The FTIR spectra of the coatings are displayed in Figure 1. For all coatings, the bands specific to HAP, originating from vibrations of $\mathrm{PO}_{4}{ }^{3-}$ groups $\left(1011-1040 \mathrm{~cm}^{-1}\right)$, were observed. The FTIR spectrum of undoped HAP revealed sharp and well-defined bands placed at $1030 \mathrm{~cm}^{-1}$ and $1080 \mathrm{~cm}^{-1}$, which can be attributed to $\left(v_{3}\right)$ symmetrical stretching vibration of the $\mathrm{PO}_{4}{ }^{3-}$ group [26]. As can be seen from Figure 1, the prominent $\mathrm{PO}_{4}{ }^{3-}$ band at $1030 \mathrm{~cm}^{-1}$ exhibited a gradual blue-shift up to $10 \mathrm{~cm}^{-1}$, becoming broader when the $\mathrm{Mg}$ ion concentrations were increased in the Ti-doped HAP coating. This result confirms that some structural disorder had occurred during the $\mathrm{Mg}$ addition. The IR spectra corresponding to TM-0, TM- 1 and TM-2 coatings showed the presence of a weak band at $1011 \mathrm{~cm}^{-1}$, which is attributed to the $v_{3-} \mathrm{PO}_{4}{ }^{3-}$ group [27]. In the literature, it has been reported that the band found at $1030 \mathrm{~cm}^{-1}$ can be attributed to apatitic phosphate, while the band at $1010 \mathrm{~cm}^{-1}$ 
to non-apatitic phosphate $[28,29]$. We also found some characteristic peaks in all spectra at around $565 \mathrm{~cm}^{-1}$ and $717 \mathrm{~cm}^{-1}$, which can be attributed to the $v_{4} \mathrm{PO}_{4}{ }^{3-}$ and $\mathrm{P}_{2} \mathrm{O}_{7}{ }^{4-}$ groups, respectively. The presence of the $\mathrm{PO}_{4}{ }^{3-}$ peaks in all the doped coatings demonstrates the apatite phase formation.

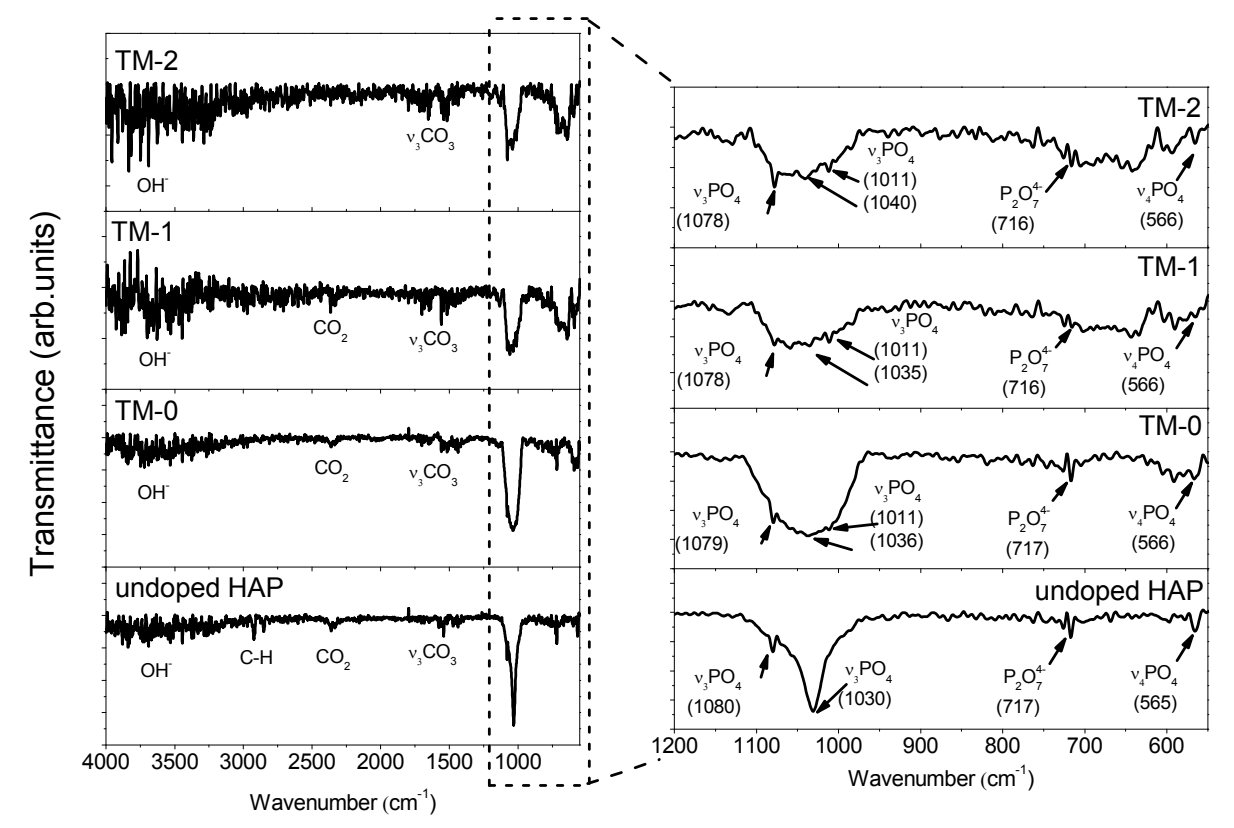

Figure 1. Fourier transform infrared spectroscopy (FTIR) spectra of the coatings.

Weak infrared (IR) bands corresponding to the $\mathrm{CO}_{3}{ }^{2-}$ group were visible in the spectral interval from 1650 to $1300 \mathrm{~cm}^{-1}$. The presence of $\mathrm{C}-\mathrm{O}$ bands is probably as a result of $\mathrm{CO}_{2}$ absorption from the atmosphere. The relative intensities of the bands corresponding to the $\mathrm{OH}^{-}$group were observed between 3600 and $3300 \mathrm{~cm}^{-1}$, being more intense in the case of the TM- 1 and TM-2 coatings. The reason is probably that the $\mathrm{Ca}^{2+}$ is replaced by $\mathrm{Mg}^{2+}$ and the increase in $\mathrm{Mg}$ concentration is compensated by $\mathrm{OH}^{-}$ions, or those of $\mathrm{HPO}_{4}{ }^{2-}$. A weak band of $\mathrm{P}_{2} \mathrm{O}_{7}{ }^{4-}$ was found in all coatings, probably due to the conversion of $\mathrm{HPO}_{4}{ }^{2-}$. In the case of doped coatings, it will be a competition between $\mathrm{Mg}^{2+}$ and $\mathrm{Ca}^{2+}$ to bond with anions, leading to a deficiency of $\mathrm{Ca}$ and a presence of water, and $\mathrm{HPO}_{4}{ }^{2-}$ is predicted. This effect was also found for the $\mathrm{Zn}$-doped hydroxyapatite coatings [30]. Tank et al. [30] explained this effect as one in which stable interstitial protons form due to the attachment of oxygen of $\mathrm{O}-\mathrm{H}$ or $\mathrm{PO}_{4}{ }^{3-}$ groups, leading to the formation of water or $\mathrm{HPO}_{4}{ }^{2-}$. Han et al. reported that the $\mathrm{OH}^{-}$groups found between 3600 and $3300 \mathrm{~cm}^{-1}$ can be a sign of the presence of the HAP phase [31]. In the case of the TM- 1 and TM-2 coatings, a weak band at $\sim 640 \mathrm{~cm}^{-1}$ was seen, appearing probably due to the substitution of the $\mathrm{OH}^{-}$group by the $\mathrm{CO}_{3}{ }^{2-}$ group. This finding was also found by Antonakos et al. [32].

\subsection{Morphology}

Figure 2 shows the AFM 3D images acquired on a $3 \times 3 \mu \mathrm{m}^{2}$ area of uncoated and coated Ti6Al4V substrates. For comparison, Ti-doped HAP coating without Mg was also presented. Note that all of the coatings have smooth surfaces with uniform growth. Based on AFM images, the following roughness parameters were calculated: $r m s, S_{\mathrm{k}}$ and $K$, being illustrated in Figure 3. 


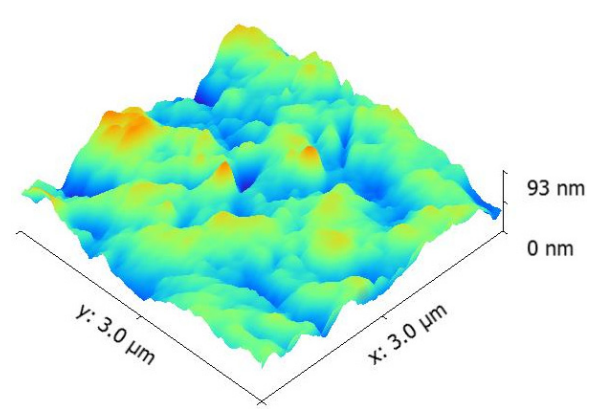

(a)

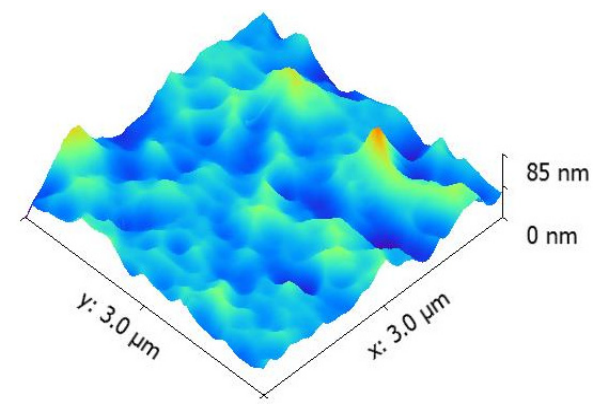

(c)

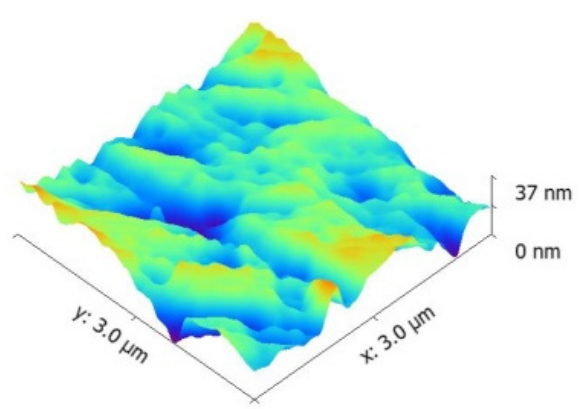

(b)

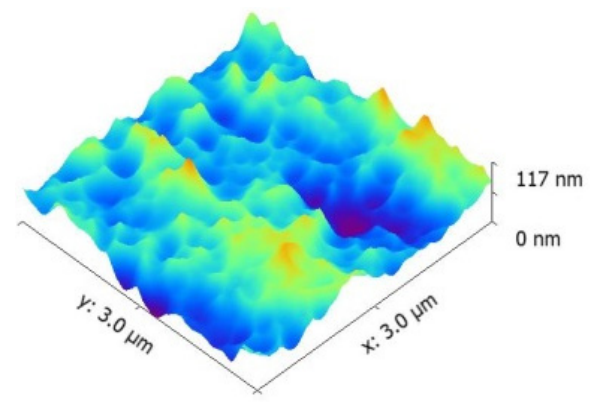

(d)

Figure 2. Atomic force microscope (AFM) images of the bare Ti6Al4V alloy and coatings deposited on Ti6Al4V substrates; for comparison, Ti-doped HAP coating without Mg was presented (TM-0). (a) Ti6Al4V; (b) TM-0; (c) TM-1; (d) TM-2.

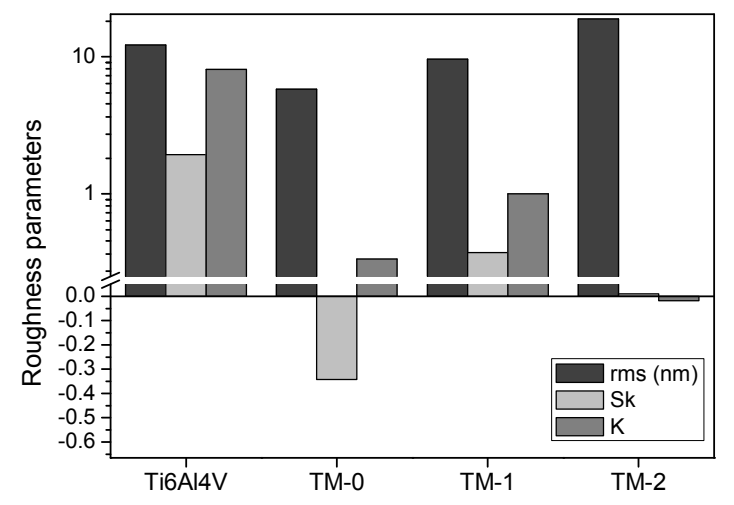

Figure 3. The roughness parameters calculated from the AFM images (rms, root mean square surface roughness; $S_{\mathrm{k}}$, skewness; $K$, kurtosis); for comparison, Ti-doped HAP coating without Mg was presented (TM-0).

The bare Ti6Al4V alloy showed $\mathrm{rms}$ roughness of approximately $12 \mathrm{~nm}$. The roughness of coated sample decreased to $5.8 \mathrm{~nm}$ for Ti-doped HAP (TM-0). After a small Mg content (TM-1), a slight increase in roughness was observed $(9.6 \mathrm{~nm})$. The increment of RF power fed to the $\mathrm{MgO}$ target led to an increase in roughness to $18.9 \mathrm{~nm}$ (TM-2).

Usually, flat surfaces have skewness parameters with values close to zero. If the skewness has positive values, the surfaces consist of a few valleys and lots of peaks. In our case, the coating without Mg addition (TM-0) had a negative skewness, indicating a lot of valleys, probably due to the polishing substrates. Both coatings with Mg addition exhibited a positive skewness, being close to zero for the TM-2 coating, indicating that this coating is uniformly distributed on the entire substrate and most of the substrate valleys were covered. 
The uncoated substrate has a high positive kurtosis, proving that the surface has high peaks and low valleys, which appeared during the polishing process. Gadelmawla et al. reported that the surfaces with few high peaks and low valleys presented kurtosis $<3$, and $>3$ for surfaces with many high peaks and low valleys [33]. In this context, the bare alloy exhibited a kurtosis value of about 8.1, which is higher than 3. The Ti- and Mg-doped coating (TM-1), prepared at low RF power fed to the $\mathrm{MgO}$ cathode, revealed a positive kurtosis value of less than 3, approximately 1 , indicating quite a small number of high peaks and low valleys, meaning that the peaks are bumpy. The Mg-doped coating (TM-2), prepared at high RF power fed to the MgO cathode, showed a negative kurtosis very close to 0 , signifying that the surface is formed of few high peaks and low valleys, meaning that many sharp peaks were found on the surface.

In the literature, it is stated that skewness and kurtosis could be used to estimate the corrosion resistance and friction performance of a surface [34,35]. Sedlacek et al. reported that a more negative skewness and a high kurtosis imply a low friction performance under dry sliding, due to the deep valleys, which act as wear particle traps [34]. Furthermore, Sedlacek et al. obtained the same results also under lubricated sliding, where the deep valleys play the role of micro reservoirs, intensifying the lubrication process [34]. The coatings under investigation in this paper exhibited kurtosis of less than 1 , indicating that the surface consists of a few high peaks and low valleys, which can imply a good friction performance. Good corrosion resistance was found when the skewness had more positive values, while negative skewness indicated pitting corrosion [35]. In our case, both Mg-doped HAP coatings proved to have positive skewness, and were expected to have superior corrosion resistance than others.

Based on the results, one may conclude that the TM- 1 coating could be a possible candidate for increasing the corrosion resistance and friction performance of the HAP coatings.

\subsection{Mechanical Properties}

Knowledge of the mechanical properties of HAP coatings is necessary in order to anticipate their performance when employed, and in particular to draw comparisons between their performance and that of natural bones [36]. HAP demonstrates unsatisfactory mechanical properties, principally in corrosive surroundings such as those found in the human body. Important progress has been reported into the microstructures of biocompatible ceramics, aimed at achieving implants with suitable mechanical properties used in hard tissue replacement [37]. Nowadays, studies are being focused on the modification of HAP by the addition of other phases or elements in order to obtain enhanced mechanical and corrosive properties [38]. To show the modifications that materials undergo, hardness is one critical parameter for evaluating the mechanical properties of a material [39]. In our previous study, it was reported that the addition of Ti to the HAP structure caused an increase in mechanical properties, as a result of the lattice deformation caused by the Ti atoms being added to the base HAP cell unit [13].

For this study, load-unload measurements from 1.0 to $5.0 \mathrm{mN}$, with a step size (dP) $0.5 \mathrm{mN}$, were performed. By growing load from 1.0 to $5.0 \mathrm{mN}$, the penetration depth increases. Thus, for preventing the influence of substrate properties, we established that the best load to investigate our coatings was $1.0 \mathrm{mN}$. For this load, the depth of the indenter is less than $10-20 \%$ of the coating thickness. The maximum penetration depth achieved at the end of the loading is less significant for the coating without $\mathrm{Mg}$ addition (TM-0), suggesting that the $\mathrm{Mg}$ addition does not have any favorable influence on the mechanical properties of Ti-doped HAP coatings. The $E$ and $H$ values obtained from load-unload measurements at $1.0 \mathrm{mN}$ are summarized in Table 3. It can be observed that both the $H$ and $E$ of the coated samples decrease with $\mathrm{Mg}$ addition in the Ti-doped HAP structure. 
Table 3. Eaverage and $H_{\text {average }}$ results of HAP-Ti coatings with and without Mg addition.

\begin{tabular}{|c|c|c|c|c|c|c|c|}
\hline Coating & Load $(\mathrm{mN})$ & $E_{\text {average }}(\mathrm{GPa})$ & $H_{\text {average }}(\mathrm{GPa})$ & $H / E$ & $H^{2} / E^{2}$ & $H^{3} / E^{2}$ (GPa) & $H^{2} / 2 E(\mathrm{GPa})$ \\
\hline TM-0 & & $87.156 \pm 1.83$ & $8.809 \pm 0.23$ & 0.1011 & 0.0102 & 0.0899 & 3382 \\
\hline TM-1 & 1.0 & $83.171 \pm 1.77$ & $8.670 \pm 0.20$ & 0.1042 & 0.0108 & 0.0942 & 3126 \\
\hline TM-2 & & $52.993 \pm 1.46$ & $5.764 \pm 0.18$ & 0.1088 & 0.0118 & 0.0681 & 880 \\
\hline
\end{tabular}

The $H / E$ ratio is called "plasticity index" and defines the elastic strain of a material to its failure [40]. A high value of this ratio indicates good elastic properties and good adhesion of the coating to the substrate. By taking into consideration this ratio, one may see that the addition of $\mathrm{Mg}$ into Si-based HAP coatings improves the elastic ability of HAP coatings. Moreover, a high $H / E$ ratio was found for TM-2, indicating good adhesion to the Ti6Al4V substrate. The $H^{3} / E^{2}$ ratio is an indicator that a material resists plastic deformation [40]. A high value indicates a good elastic behaviour. The TM-1 coatings exhibited the highest $H^{3} / E^{2}$ ratio, meaning the best elastic properties, followed by TM- 0 and TM-2. The $H^{2} / 2 E$ ratio describes resistance to the effect of external forces, known as the modulus of resilience [40]. It can be seen that the TM-0 has the highest $H^{2} / 2 E$ ratio, indicating a good ability to recover after applying external forces. It can be observed that the TM-2 exhibited high $H / E$ and $H^{3} / E^{2}$ ratios, indicating good deformation to yielding, while TM-1 showed high $H^{3} / E^{2}$ and $H^{2} / 2 E$ ratios, meaning higher plastic properties.

\subsection{In Vitro Electrochemical Behaviour}

The human body is a corrosive environment for any artificial materials inserted into it, especially for metallic surfaces such as implants. For this reason, it is very important to investigate the behaviour of artificial material in contact with solutions that mimic human physiological solutions. Electrochemical tests are the most common form of analysis for evaluating a material's behaviour in corrosive solution.

The evolution of the open circuit potential $\left(E_{\mathrm{OC}}\right)$ after $6 \mathrm{~h}$ of immersion in SBF at $37^{\circ} \mathrm{C}$ is shown in Figure 4. Tafel curves of the coatings and uncoated Ti6Al4V substrate are presented Figure 5. Electrochemical parameters, corrosion potential $\left(E_{i=0}\right)$ and corrosion current density $\left(i_{\text {corr }}\right)$ were extracted from Tafel curves by the extrapolation technique, and the results are presented in Table 4 . Taking into account the electrochemical parameters, the porosity $(P)$ was calculated, using Elsener's empirical equation [41]. The protective efficiency $\left(P_{\mathrm{e}}\right)$ was also determined by a formula reported in [24]. Mansfeld [42] and Scully [43] described how the $E_{\mathrm{OC}}$ potential is the parameter that is related to the nobility of a surface at contact with a corrosive medium. According to Figure 4, for all coatings the potential exhibited some oscillation at the beginning of the test, indicating higher film stability to breakdown. After $2 \mathrm{~h}$ of immersion, it can be noted that there are fewer oscillations, suggesting that all the investigated surfaces started to be covered by stable protective oxides which are resistant to chemical dissolution in SBF solution. Both Mg-doped coatings have a similar evolution of $E_{\mathrm{OC}}$ potential after $2 \mathrm{~h}$, having a more electropositive $E_{\mathrm{OC}}$ value than of uncoated Ti6Al4V alloy. TM- 0 exhibited more electronegative $E_{\mathrm{OC}}$ value, demonstrating that this coating is more or less affected by the SBF solution.

Table 4. Electrochemical parameters of the coatings tested in simulated body fluid (SBF) solution at $37^{\circ} \mathrm{C}\left(E_{i=0}\right.$, corrosion potential; $i_{\text {corr }}$, corrosion current density; $R_{\mathrm{p}}$, polarization resistance; $P$, porosity; $P_{\mathrm{e}}$, protection efficiency).

\begin{tabular}{cccccc}
\hline Sample & $\boldsymbol{E}_{\boldsymbol{i}=\mathbf{0}}(\mathbf{m V})$ & $\boldsymbol{i}_{\text {corr }}\left(\mathbf{n A} / \mathbf{c m}^{\mathbf{2}}\right)$ & $\boldsymbol{R}_{\mathbf{p}}(\mathbf{k} \boldsymbol{\Omega})$ & $\boldsymbol{P}$ & $\boldsymbol{P}_{\mathbf{e}}(\mathbf{\%})$ \\
\hline Ti6Al4V & -94 & 45.76 & 2345 & - & - \\
TM-0 & -209 & 27.36 & 1825 & 1.14 & 40.2 \\
TM-1 & -67 & 10.02 & 3294 & 0.69 & 78.1 \\
TM-2 & -81 & 26.48 & 3092 & 0.75 & 42.1 \\
\hline
\end{tabular}




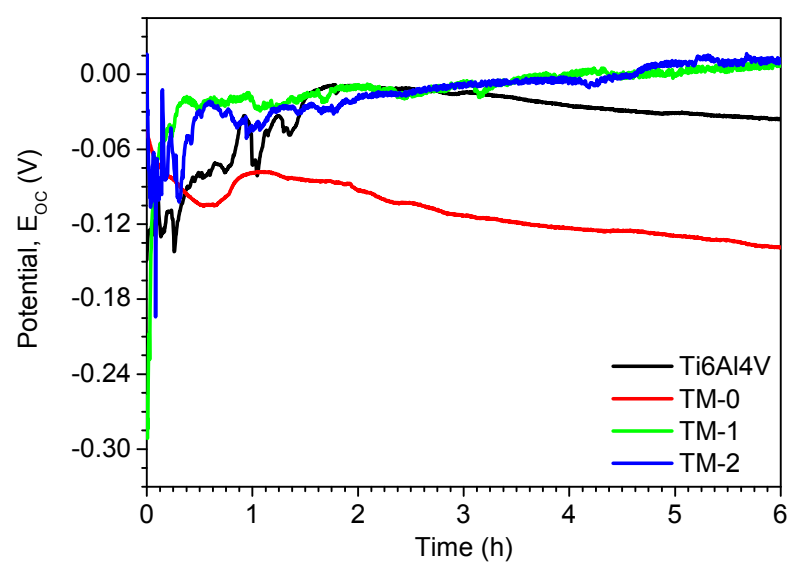

Figure 4. Open circuit potential of the studied samples tested in SBF at $37^{\circ} \mathrm{C}$.

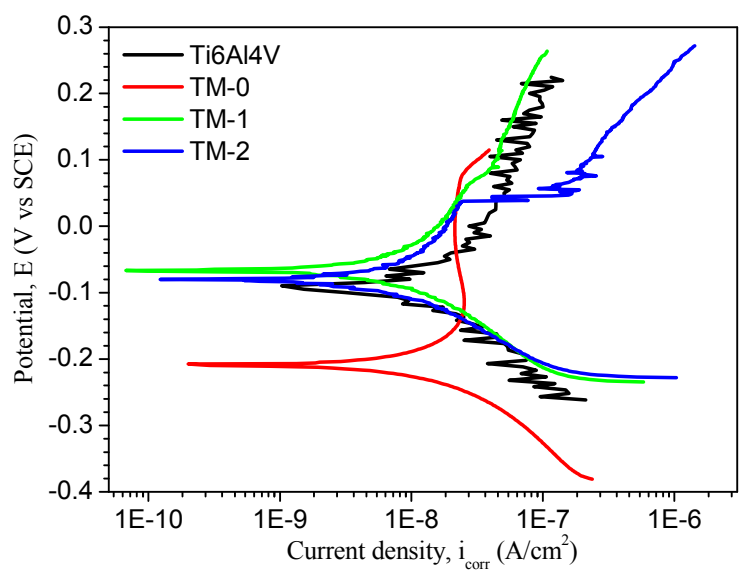

Figure 5. Tafel curves of studied samples tested in SBF at $37^{\circ} \mathrm{C}$.

Corrosion resistance plays an essential role in biomedical applications, because any material, especially a metallic one, starts to degrade in contact with body fluids, leading to the formation of corrosion products that will affect the tissue around the implant. It is very important to modify the surface of metallic implants with coatings based on calcium and phosphorus in order to delay the corrosive process [44]. It is generally recognized that the corrosion resistance of metallic surfaces can be estimated by several criteria, as an electropositive $\left(E_{i=0}\right)$ and low $i_{\text {corr }}$ and high $R_{\mathrm{p}}$ values reveal good anti-corrosive properties [45]. For all coatings, it is possible to say that these significantly improve the corrosion behaviour of the Ti6Al4V alloy. According to the $i_{\text {corr }}$ parameter, all investigated coatings have lower $i_{\text {corr }}$ values than uncoated Ti6Al4V alloy. The addition of Mg into the HAP-Ti structure also leads to a decrease in $i_{\text {corr }}$ value over undoped Mg coating (TM-0), whatever the deposition conditions, signifying an improvement of the resistance to corrosion. An increment of RF power fed to the $\mathrm{MgO}$ target has a significant influence on the electrochemical characteristics of the Ti-doped HAP coatings, leading to the deterioration of corrosion performance.

Comparison of the $R_{\mathrm{p}}$ values showed that the coating with added $\mathrm{Mg}$ revealed a higher polarization resistance in SBF than that of uncoated Ti6Al4V alloy and coating without Mg (TM-0). Regarding the porosity $(P)$, it can be observed that the values of the Mg-doped coatings were not so different. Somehow, the increase of $\mathrm{Mg}$ content leads to a slight increase of porosity. The coating with $\mathrm{Mg}$ addition has the highest porosity value. This effect can be an advantage for cell growth, proliferation and differentiation. In regard to protective efficiency $\left(P_{\mathrm{e}}\right)$, the best value was found for the TM-1 sample (78.1\%), a coating with low Mg content. It seems that the Mg increment does not enhance resistance to the corrosive effect of SBF. 
The electrochemical results of Mg-doped HAP-Ti coatings revealed that the electrochemical parameters increase with the increase of surface roughness parameters $\left(R_{\mathrm{a}}\right)$. Therefore, it can be concluded that roughness can be regarded as an important parameter effect on corrosion resistance. Consequently, the specimens coated with $\mathrm{Mg}$-doped coatings presented a superior barrier effect to preserve the uncoated substrate and also to the coating without $\mathrm{Mg}$ addition. Corrosion involves the penetration of $\mathrm{Cl}^{-}$ions and $\mathrm{H}_{2} \mathrm{O}$ through the depth found on coated surfaces and accelerates the electrochemical reactions that take place at the substrate-coating interface [46]. A surface profiler (Dektak 150, Bruker, Berlin, Germany) was used to evaluate the roughness of the corroded surfaces on a large area of $800 \mu \mathrm{m} \times 800 \mu \mathrm{m}$. The $R_{\mathrm{a}}, \mathrm{rms}$ and $S_{\mathrm{k}}$ parameters were calculated for each investigated sample (Table 5). Roughness of the samples before electrochemical tests was also measured in order to compare the effect of the corrosion tests. According to the roughness parameters, the TM- 0 sample is more affected by the SBF solution than the TM- 1 or TM-2, indicating that Mg addition improves the corrosion resistance of Ti-doped HAP in SBF. Note that the TM-1 exhibited a skewness value close to zero, signifying that the hills found before corrosion were almost leveled, and leading to a flat surface. TM-1 and TM-2 samples revealed small differences in roughness parameters before and after corrosion compared to those of uncoated Ti6Al4V and TM-0, showing that the introduction of $\mathrm{Mg}$ can reduce the dissolution rate of the HAP coating in the SBF solution. As an example, Figure 6 shows 3D mapping of the TM-1 coating, which proved to have the best corrosion resistance, before and after electrochemical tests in the SBF solution. One may observe that the surface of the TM- 1 coating is not affected by the SBF attack. This effect corresponds with the electrochemical results.

Table 5. Roughness of the investigated samples measured on a large area by surface profilometry before and after electrochemical tests.

\begin{tabular}{ccccccc}
\hline \multirow{2}{*}{ Samples } & \multicolumn{3}{c}{ Before Corrosion Tests } & \multicolumn{3}{c}{ After Corrosion Tests } \\
\cline { 2 - 7 } & $\boldsymbol{R}_{\mathbf{a}} \mathbf{( n m )}$ & $\mathbf{r m s} \mathbf{( n m )}$ & $\boldsymbol{S}_{\mathbf{k}}$ & $\boldsymbol{R}_{\mathbf{a}} \mathbf{( n m )}$ & $\mathbf{r m s} \mathbf{( n m )}$ & $\boldsymbol{S}_{\mathbf{k}}$ \\
\hline Ti6Al4V & 52.2 & 87.4 & 31.110 & 72.8 & 98.6 & 0.218 \\
TM-0 & 57.9 & 84.7 & 0.201 & 68.4 & 97.1 & 0.140 \\
TM-1 & 28.2 & 35.9 & 0.179 & 27.5 & 31.7 & -0.012 \\
TM-2 & 29.8 & 40.2 & 1.731 & 33.5 & 41.4 & 0.218 \\
\hline
\end{tabular}

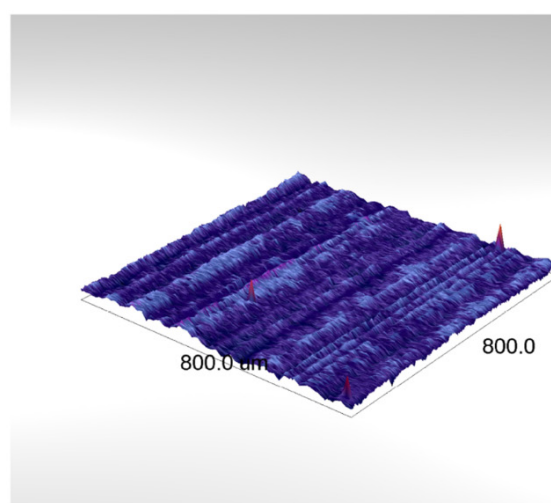

(a)

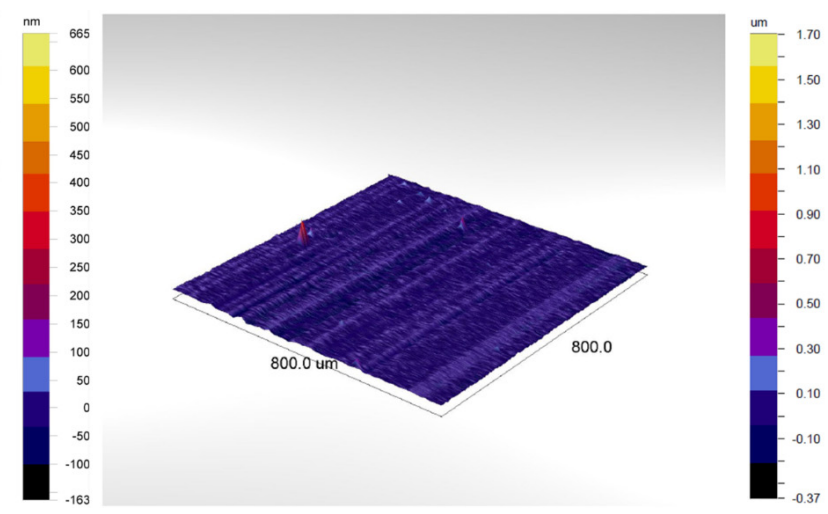

(b)

Figure 6. 3D mapping images of the TM-1 coating deposited on Ti6Al4V substrates: (a) Before electrochemical tests; (b) After electrochemical tests. The investigated area was $800 \mu \mathrm{m} \times 800 \mu \mathrm{m}$.

\subsection{In Vitro Biological Properties}

SaOS-2 cells were seeded directly on standard titanium alloy (Ti6Al4V) or the coated surfaces in order to investigate bone cell adhesion and morphology. Figure 7 shows that attached cell numbers seemed to be higher on TM- 1 and TM-2 than on Ti6Al4V, indicating preferable adhesion conditions 
on the novel coatings. The relative densities of living cells (Table 6) proved those differences to be significant after the first day of seeding. On day 3, however, cell numbers were similar on all three surfaces. SaOS-2 osteoblasts displayed their typical polygonal shape with prominent actin stress fibres visible on all tested surfaces.

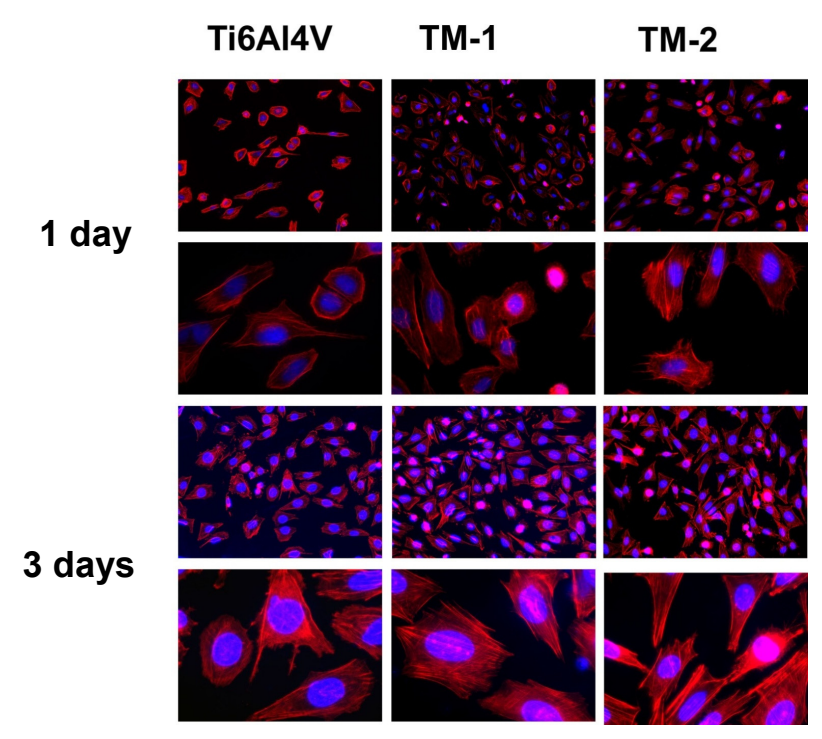

Figure 7. Adhesion and morphology of SaOS-2 cells after 1 day and 3 days of culture on Ti6Al4V, TM-1, and TM-2 coatings. Actin cytoskeleton appears in red, nuclei in blue fluorescence. Magnifications are $100 \times$ and $400 \times$, respectively.

Table 6. Relative numbers of living cells.

\begin{tabular}{ccc}
\hline Surface & 1 Day & 3 Days \\
\hline Ti6Al4V & $42.33 \pm 6.15^{\mathrm{a}}$ & $81.83 \pm 13.35^{\mathrm{a}}$ \\
TM-1 & $57.5 \pm 6.98^{\mathrm{b}}$ & $78.0 \pm 18.3^{\mathrm{a}}$ \\
TM-2 & $52.67 \pm 5.64^{\mathrm{b}}$ & $68.33 \pm 18.17^{\mathrm{a}}$ \\
\hline
\end{tabular}

Note: Different superscript letter within column indicates $p<0.05$.

Live/dead fluorescence staining was used to determine osteoblast viability after 1 or 3 days in direct contact with standard alloy or the coated surfaces (Figure 8). Virtually all cells were vital (green), indicating no cytotoxic distress exerted by the novel coatings. Notably, after three days of contact this assay also showed more attached vital cells per microscopic view on TM-1 and TM-2 coatings compared to the standard titanium alloy, thus supporting the outcome of the adhesion test.

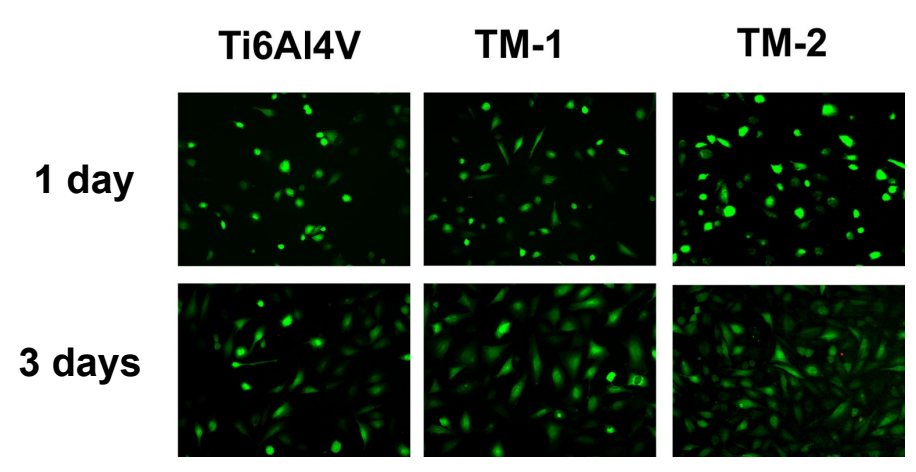

Figure 8. Viability assay of SaOS-2 cells after 1 day and 3 days of culture on Ti6Al4V, TM-1, and TM-2 coatings. Living cells emit green, dead cells display red fluorescence. Magnification is $100 \times$. 
In vitro biological results demonstrated that all tested surfaces are biocompatible, accepting the adhesion and growth of bone cells. Whereas cell viability is excellent on an uncoated alloy and the novel surfaces, both novel coatings seem to accelerate cell adhesion compared to Ti6Al4V. Regarding the cell viability, both novel coatings had very similar properties.

Magnesium plays an important role in the control of biochemical reactions, therefore influencing crucial physiological functions such as nucleic acid metabolism, protein synthesis and energy production. It was expected that the coatings containing $\mathrm{Mg}$ would show lower cell numbers than of uncoated Ti6Al4V. It has already been demonstrated that cell adhesion and proliferation of MG63 osteosarcoma cells is inhibited in direct contact with pure Mg surfaces or Mg-based coatings [47,48]. A possible explanation for this could be due to the $\mathrm{Mg}$ ions being released from the surface of the implant. Degradation of $\mathrm{Mg}$ in contact with human physiological solution involves hydrogen decomposition and an elevated $\mathrm{pH}$ at the implant surface. Both factors can strongly affect initial osteoblast adhesion and delay cell spreading and proliferation [47]. In this study, the TM-1 coating was less affected by the SBF corrosive attack, probably leading to lesser hydrogen decomposition. This result might explain the slightly better cell spreading and proliferation on the TM- 1 coating compared to TM-2.

On the other hand, extracellular $\mathrm{Mg}^{2+}$ and $\mathrm{Ca}^{2+}$ ions are both essential for the adhesion and proliferation of human osteoblasts and cannot compensate each other [49]. Although the cell culture medium contained both ions, the specific $\mathrm{Mg}^{2+}$ concentration may be higher at the immediate interface between bone cells and implant surface due to magnesium ions released from the coating. This might accelerate initial cell adhesion on both Mg-doped coatings compared to Ti6Al4V alloy, leading to significantly higher numbers of adherent vital cells $24 \mathrm{~h}$ after seeding. This early positive effect of $\mathrm{Mg}^{2+}$ on osteoblast proliferation seems later to be neutralized by hydrogen evolution and/or alkalinisation of the implant surface, as cell numbers on both $\mathrm{Mg}$ coatings were statistically indiscernible from those on Ti6Al4V on day 3.

The free $\mathrm{Mg}^{2+}$ concentration is the regulatory agent for cell proliferation, leading to a coordinate physiological response, which is an important step immediately after the insertion of medical implants [50]. Rubin [50] further found that there is an optimal $\mathrm{Mg}^{2+}$ concentration for DNA and protein synthesis. A lower or higher magnesium level will lead to a decline in both processes and thus will inhibit cell proliferation. Furthermore, Leid et al. showed that the formation of a calcium phosphate mineral matrix is affected by a high free $\mathrm{Mg}^{2+}$ level [51]. In bone formation and healing, the formation of this mineral matrix is an important phase, and thus it is crucial to have the optimal amount of free $\mathrm{Mg}^{2+}$ in the coating.

\section{Conclusions}

The consequence of $\mathrm{Mg}$ and Ti addition on the mechanical characteristics, corrosion behavior and cell viability of a HAP system was studied. The following conclusions can be drawn from this research:

- Surface roughness of the coatings increases with Mg incorporation into a Ti-doped HAP structure. Additionally, with increasing RF power fed to the $\mathrm{MgO}$ cathode there is intensification in the roughness of the coating surface.

- The decrease in the surface roughness plays an important role in increasing the corrosion resistance.

- Corrosion results show that coating obtained at low RF power fed to the MgO target led to a decrease in the current density compared with other coatings and bare alloy, suggesting a high corrosion performance.

- Mg- and Ti-doped HAP coatings obtained at low RF power fed to the MgO target provided the material with high protection efficiency $(78.1 \%)$ to the corrosive SBF attack, indicating a higher corrosion resistance. 
- It can be concluded that the elastic modulus of the coated samples decreases with Mg addition in the HAP structure, especially in the case of the coatings with high Mg concentration (53 GPa).

- All tested surfaces are non-cytotoxic, as they support the adhesion and growth of bone cells.

- $\mathrm{Mg}$ ions seem to accelerate initial osteoblast adhesion and proliferation.

The results obtained from this study demonstrate that the novel coatings are promising candidates for orthopaedic applications. Further in vivo tests will be needed for validation of the in vitro results.

Acknowledgments: This work was supported under a grant of the Bilateral cooperation Turkey-Romania Project (RO599/2013and TUBITAK 112R020). The work was also supported under two grants financed by the Romanian National Authority for Scientific Research (CNCS-UEFISCDI), project number PN-II-PT-PCCA-2014-212 and number PN-III-P2-2.1-PED-2016-1854, within PNCDI III.

Author Contributions: Thomas K. Monsees and Alina Vladescu designed the research; Thomas K. Monsees, Radwan Abdulgader and Robin Booysen performed the in vitro experiments; Mariana Braic and Adrian Kiss prepared the coatings; Alina Vladescu performed the AFM and 3D mapping; Iulian Pana did the FTIR analysis; Cosmin Mihai Cotrut performed the electrochemical tests; Funda Ak Azem and Isil Birlik completed the nanoindentation tests; Alina Vladescu, Mariana Braic and Thomas K. Monsees analyzed the data and provided valuable input in data interpretation; Thomas K. Monsees and Alina Vladescu supervised the work and wrote the first draft of the article; all authors reviewed and approved the work.

Conflicts of Interest: The authors declare no conflict of interest. The founding sponsors had no role in the design of the study; in the collection, analyses, or interpretation of data; in the writing of the manuscript, and in the decision to publish the results.

\section{References}

1. Sedelnikova, M.B.; Sharkeev, Y.P.; Komarova, E.G.; Khlusov, I.A.; Chebodaeva, V.V. Structure and properties of the wollastonite calcium phosphate coatings deposited on titanium and titanium niobium alloy using microarc oxidation method. Surf. Coat. Technol. 2016, 307, 1274-1283. [CrossRef]

2. Yamaguchi, T.; Tanaka, Y.; Ide-Ektessabi, A. Fabrication of hydroxyapatite thin films for biomedical applications using RF magnetron sputtering. Nucl. Instrum. Methods Phys. Res. Sect. B Beam Interact. Mater. Atoms 2006, 249, 723-725. [CrossRef]

3. Dorozhkin, S.V. Calcium orthophosphate deposits: Preparation, properties and biomedical applications. Mater. Sci. Eng. C 2015, 55, 272-326. [CrossRef] [PubMed]

4. Dorozhkin, S.V.; Epple, M. Biological and medical significance of calcium phosphates. Angew. Chem. Int. Ed. 2002, 41, 3130-3146. [CrossRef]

5. Pardun, K.; Treccani, L.; Volkmann, E.; Streckbein, P.; Heiss, C.; Destri, G.L.; Marletta, G.; Rezwan, K. Mixed zirconia calcium phosphate coatings for dental implants: Tailoring coating stability and bioactivity potential. Mater. Sci. Eng. C 2015, 48, 337-346. [CrossRef] [PubMed]

6. Boyd, A.R.; Rutledge, L.; Randolph, L.D.; Meenan, B.J. Strontium-substituted hydroxyapatite coatings deposited via a co-deposition sputter technique. Mater. Sci. Eng. C 2015, 46, 290-300. [CrossRef] [PubMed]

7. López, E.O.; Rossi, A.L.; Archanjo, B.S.; Ospina, R.O.; Mello, A.; Rossi, A.M. Crystalline nano-coatings of fluorine-substituted hydroxyapatite produced by magnetron sputtering with high plasma confinement. Surf. Coat. Technol. 2015, 264, 163-174. [CrossRef]

8. DeGroot, K.; DePutter, C.; Smitt, P.; Driessen, A. Mechanical failure of artificial teeth made of dense calcium hydroxyapatite. Sci. Ceram. 1981, 11, 433-437.

9. Revilla-López, G.; Bertran, O.; Casanovas, J.; Turon, P.; Puiggalí, J.; Alemán, C. Effects of hydroxyapatite (0001) $\mathrm{Ca}^{2+} / \mathrm{Mg}^{2+}$ substitution on adsorbed D-ribose ring puckering. RSC Adv. 2016, 6, 69634-69640. [CrossRef]

10. Gopi, D.; Karthika, A.; Nithiya, S.; Kavitha, L. In vitro biological performance of minerals substituted hydroxyapatite coating by pulsed electrodeposition method. Mater. Chem. Phys. 2014, 144, 75-85. [CrossRef]

11. Vijayalakshmi, V.; Dhanasekaran, P. Synthesis and structural properties characterization of $\mathrm{Ap} / \mathrm{MgO}$ nanocomposites for biomedical applications. Biol. Med. Case Rep. 2017, 1, 1-6.

12. Farzadi, A.; Bakhshi, F.; Solati-Hashjin, M.; Asadi-Eydivand, M.; Osman, N.A.A. Magnesium incorporated hydroxyapatite: Synthesis and structural properties characterization. Ceram. Int. 2014, 40, 6021-6029. [CrossRef] 
13. Vladescu, A.; Padmanabhan, S.C.; Ak Azem, F.; Braic, M.; Titorencu, I.; Birlik, I.; Morris, M.A.; Braic, V. Mechanical properties and biocompatibility of the sputtered Ti doped hydroxyapatite. J. Mech. Behav. Biomed. Mater. 2016, 63, 314-325. [CrossRef] [PubMed]

14. Lósarczyk, A.; Ima, A.Z.; Aszkiewicz, Z.P.; Zczepaniak, J.S.; Za, A.H.D.E.A.; Hróĝcicka, A.C. The Influence of Titanium on Physicochemical Properties of Ti-modified Hydroxyapatite Materials. Mater. Ceram. 2010, 62, 369-375.

15. Pichugin, V.F.; Surmenev, R.A.; Shesterikov, E.V.; Ryabtseva, M.A.; Eshenko, E.V.; Tverdokhlebov, S.I.; Prymak, O.; Epple, M. The preparation of calcium phosphate coatings on titanium and nickel-titanium by rf-magnetron-sputtered deposition: Composition, structure and micromechanical properties. Surf. Coat. Technol. 2008, 202, 3913-3920. [CrossRef]

16. Nelea, V.; Morosanu, C.; Iliescu, M.; Mihailescu, I.N. Microstructure and mechanical properties of hydroxyapatite thin films grown by RF magnetron sputtering. Surf. Coat. Technol. 2003, 173, 315-322. [CrossRef]

17. Surmeneva, M.A.; Vladescu, A.; Surmenev, R.A.; Pantilimon, C.M.; Braic, M.; Cotrut, C.M. Study on a hydrophobic Ti-doped hydroxyapatite coating for corrosion protection of a titanium based alloy. RSC Adv. 2016, 6, 87665-87674. [CrossRef]

18. Sandhyarani, M.; Rameshbabu, N.; Venkateswarlu, K.; Ravisankar, K.V.; Ashok, M.; Anandan, S. Photocatalytic and Antibacterial Activity of Titanium, Fluorine and Silver Co-Substituted Hydroxyapatite. Int. J. Mod. Phys. Conf. Ser. 2013, 22, 268-277. [CrossRef]

19. Wakamura, M. Photocatalysis by calcium hydroxyapatite modified with Ti (IV). Fujitsu Sci. Tech. J. 2005, 41, 181-190.

20. Wakamura, M.; Hashimoto, K.; Watanabe, T. Photocatalysis by calcium hydroxyapatite modified with Ti(IV): Albumin decomposition and bactericidal effect. Langmuir 2003, 19, 3428-3431. [CrossRef]

21. Tsukada, M.; Wakamura, M.; Yoshida, N.; Watanabe, T. Band gap and photocatalytic properties of Ti-substituted hydroxyapatite: Comparison with anatase- $\mathrm{TiO}_{2}$. J. Mol. Catal. A Chem. 2011, 338, 18-23. [CrossRef]

22. Vladescu, A.; Braic, M.; Azem, F.A.; Titorencu, I.; Braic, V.; Pruna, V.; Kiss, A.; Parau, A.C.; Birlik, I. Effect of the deposition temperature on corrosion resistance and biocompatibility of the hydroxyapatite coatings. Appl. Surf. Sci. 2015, 354, 373-379. [CrossRef]

23. Bull, S.J. Nanoindentation of coatings. J. Phys. D Appl. Phys. 2005, 38, 393-413. [CrossRef]

24. Dudin, S.; Cotrut, C.M.; Dinu, M.; Zykova, A.; Parau, A.C.; Yakovin, S.; Vladescu, A. Comparative study of the hydroxyapatite coatings prepared with/without substrate bias. Ceram. Int. 2017, 43, 14968-14975. [CrossRef]

25. ASTM G5-94 Standard Reference Test Method for Making Potentiostatic and Potentiodynamic Anodic Polarization Measurements; ASTM: West Conshohocken, PA, USA, 1999.

26. Rehman, I.; Bonfield, W. Characterization of hydroxyapatite and carbonated apatite by photo acoustic FTIR spectroscopy. J. Mater. Sci. Mater. Med. 1997, 8, 1-4. [CrossRef] [PubMed]

27. Plowright, R.; Belton, D.J.; Kaplan, D.L.; Perry, C.C. Quantifying the efficiency of Hydroxyapatite Mineralising Peptides. Sci. Rep. 2017, 7, 7681. [CrossRef] [PubMed]

28. Bala, Y.; Farlay, D.; Delmas, P.D.; Meunier, P.J.; Boivin, G. Time sequence of secondary mineralization and microhardness in cortical and cancellous bone from ewes. Bone 2010, 46, 1204-1212. [CrossRef] [PubMed]

29. Delgado-López, J.M.; Iafisco, M.; Rodríguez, I.; Tampieri, A.; Prat, M.; Gómez-Morales, J. Crystallization of bioinspired citrate-functionalized nanoapatite with tailored carbonate content. Acta Biomater. 2012, 8, 3491-3499. [CrossRef] [PubMed]

30. Tank, K.P.; Sharma, P.; Kanchan, D.K.; Joshi, M.J. FTIR, powder XRD, TEM and dielectric studies of pure and zinc doped nano-hydroxyapatite. Cryst. Res. Technol. 2011, 46, 1309-1316. [CrossRef]

31. Han, J.K.; Song, H.Y.; Saito, F.; Lee, B.T. Synthesis of high purity nano-sized hydroxyapatite powder by microwave-hydrothermal method. Mater. Chem. Phys. 2006, 99, 235-239. [CrossRef]

32. Antonakos, A.; Liarokapis, E.; Leventouri, T. Micro-Raman and FTIR studies of synthetic and natural apatites. Biomaterials 2007, 28, 3043-3054. [CrossRef] [PubMed]

33. Gadelmawla, E.S.; Koura, M.M.; Maksoud, T.M.A.; Elewa, I.M.; Soliman, H.H. Roughness parameters. J. Mater. Process. Technol. 2002, 123, 133-145. [CrossRef] 
34. Sedlaček, M.; Vilhena, L.M.S.; Podgornik, B.; Vižintin, J. Surface topography modelling for reduced friction. Stroj. Vestnik J. Mech. Eng. 2011, 57, 674-680. [CrossRef]

35. Evgeny, B.; Hughes, T.; Eskin, D. Effect of surface roughness on corrosion behaviour of low carbon steel in inhibited 4M hydrochloric acid under laminar and turbulent flow conditions. Corros. Sci. 2016, 103, 196-205. [CrossRef]

36. Mejias, A.; Candidato, R.T.; Pawowski, L.; Chicot, D. Mechanical properties by instrumented indentation of solution precursor plasma sprayed hydroxyapatite coatings: Analysis of microstructural effect. Surf. Coat. Technol. 2016, 298, 93-102. [CrossRef]

37. Tang, C.Y.; Uskokovic, P.S.; Tsui, C.P.; Veljovic, D.; Petrovic, R.; Janackovic, D. Influence of microstructure and phase composition on the nanoindentation characterization of bioceramic materials based on hydroxyapatite. Ceram. Int. 2009, 35, 2171-2178. [CrossRef]

38. Batory, D.; Gawroński, J.; Kaczorowski, W.; Niedzielska, A. C-HAp composite layers deposited onto AISI 316L austenitic steel. Surf. Coat. Technol. 2012, 206, 2110-2114. [CrossRef]

39. Mousa, H.M.; Hussein, K.H.; Woo, H.M.; Park, C.H.; Kim, C.S. One-step anodization deposition of anticorrosive bioceramic compounds on AZ31B magnesium alloy for biomedical application. Ceram. Int. 2015, 41, 10861-10870. [CrossRef]

40. Pintaude, G. Introduction of the Ratio of the Hardness to the Reduced Elastic Modulus for Abrasion. In Tribology_Fundamentals and Advancements; Jürgen, G., Ed.; InTech: Rijeka, Croatia, 2013; pp. 217-230.

41. Elsener, B.; Rota, A.; Bohni, H. Impedance study on the corrosion of PVD and CVD titanium nitride coatings. Mater. Sci. Forum 1989, 29, 44-45. [CrossRef]

42. Mansfeld, F. The Polarization Resistance Technique for Measuring Corrosion Currents. Adv. Corros. Sci. Technol. 1976, 6, 163-262.

43. Scully, J.R. Polarization resistance method for determination of instantaneous corrosion rates. Corrosion 2000, 56, 199-217. [CrossRef]

44. Jakubowicz, J.; Adamek, G.; Jurczyk, M.U.; Jurczyk, M. 3D surface topography study of the biofunctionalized nanocrystalline Ti-6Zr-4Nb/Ca-P. Mater. Charact. 2012, 70, 55-62. [CrossRef]

45. Radin, S.R.; Ducheyne, P. The effect of calcium phosphate ceramic composition and structure on in vitro behavior. II. Precipitation. J. Biomed. Mater. Res. 1993, 27, 35-45. [CrossRef] [PubMed]

46. Kwok, C.T.; Wong, P.K.; Cheng, F.T.; Man, H.C. Characterization and corrosion behavior of hydroxyapatite coatings on Ti6Al4V fabricated by electrophoretic deposition. Appl. Surf. Sci. 2009, 255, 6736-6744. [CrossRef]

47. Wagener, V.; Schilling, A.; Mainka, A.; Hennig, D.; Gerum, R.; Kelch, M.L.; Keim, S.; Fabry, B.; Virtanen, S. Cell Adhesion on Surface-Functionalized Magnesium. ACS Appl. Mater. Interfaces 2016, 8, 11998-12006. [CrossRef] [PubMed]

48. Abed, E.; Moreau, R. Importance of melastatin-like transient receptor potential 7 and cations (magnesium, calcium) in human osteoblast-like cell proliferation. Cell Prolif. 2007, 40, 849-865. [CrossRef] [PubMed]

49. Takeichi, M.; Okada, T.S. Roles of magnesium and calcium ions in cell-to-substrate adhesion. Exp. Cell Res. 1972, 74, 51-60. [CrossRef]

50. Rubin, H. The membrane, magnesium, mitosis ( MMM ) model of cell proliferation control. Magnes. Res. 2005, 18, 268-274. [PubMed]

51. Leidi, M.; Dellera, F.; Mariotti, M.; Maier, J.A.M. High magnesium inhibits human osteoblast differentiation in vitro. Magnes. Res. 2011, 24, 1-6. [PubMed]

(C) 2017 by the authors. Licensee MDPI, Basel, Switzerland. This article is an open access article distributed under the terms and conditions of the Creative Commons Attribution (CC BY) license (http://creativecommons.org/licenses/by/4.0/). 